\title{
Covid-19 Döneminde Hemşirelik Öğrencilerinde Teknoloji Bağımlılığı
}

\author{
Gülşah KÖRPE*, Leyla KÜÇÜK**
}

$\ddot{O} \mathbf{z}$

Amaç: Çalışmamızda Covid-19 sürecinde teknolojiye olan ilginin artması göz önüne alınarak hemşirelik öğrencilerinde teknoloji bağımlılı̆̆ının düzeyinin belirlenmesi amaçlanmıştır.

Yöntem: Çalışma bir özel üniversitede bulunan 362 hemşirelik öğrencisiyle yürütülmüştür. Çalışmada verilerin toplanmasında Sosyodemografik Form ve Teknoloji Bağımlılı̆̆ Ölçeği kullanılmıştır. Verilerin değerlendirilmesinde SPSS 22.0 paket programı kullanılmıştır. Verilerin normal dağılmadığı tespit edildiği için yüzde, sayı ve parametrik olmayan testlerle veriler çözümlenmiştir.

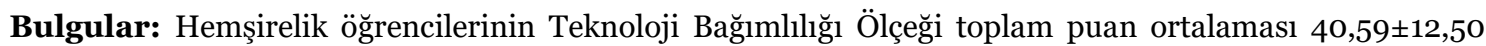

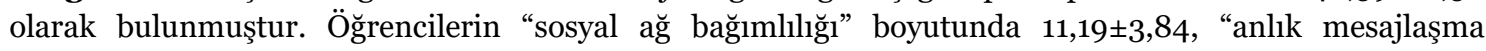

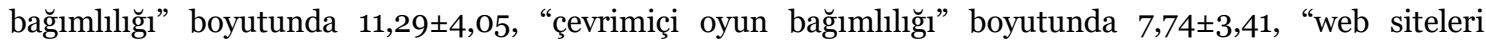
bağımlılı̆̆ı" boyutunda 10,36 $\pm 4,12$ puan ortalamasına sahip olduğu belirlenmiştir. Ayrıca pandemi sonrası teknoloji ile geçirilen saat miktarı ile ölçek puan ortalaması arasında istatistiksel açıdan anlamlı bir fark bulunmuştur.

Sonuç: Hemşirelik öğrencilerinin teknoloji bağımlılı̆̆ düzeyleri düşük düzey bağımlı olarak bulunmuştur. Teknolojinin kullanılırken dikkat edilmesi gereken en önemli konu amaca yönelik kullanımdır ve o anki kullanım amacına göre hem uğraş hem de süre anlamında sınırlandırmanın olması gerekmektedir. Eğer amaçsız ve süre sınırı olmadan, sadece eğlence amaçlı kullanılırsa, zamanın iyi kullanılmayarak zaman yönetimi becerisinin gelişememesi ya da zayıflaması gibi istenmeyen sonuçlara neden olabilir.

Anahtar Sözcükler: Hemşirelik öğrencileri, teknoloji, bağımlılı, Covid-19.

\section{Technology Addiction in Nursing Students in the Covid-19 Period}

\begin{abstract}
Aim: In our study, it was aimed to determine the level of technology addiction in nursing students, taking into account the increasing interest in technology during the Covid-19 process.

Method: The study was conducted with 362 nursing students at a private university. Sociodemographic Form and Technology Addiction Scale were used to collect data in the study. SPSS 22.0 package program was used to evaluate the data. Since it was determined that the data were not normally distributed, the data were analyzed with percentage, number and non-parametric tests.
\end{abstract}

Özgün Araştırma Makalesi (Original Research Article)

Geliş / Received: 12.08.2021 \& Kabul / Accepted: 08.12.2021

DOI: https://doi.org/10.38079/igusabder.981591

* Doktora Öğrencisi, İstanbul Üniversitesi-Cerrahpaşa, Lisansüstü Eğitim Enstitüsü, Ruh Sağlığı ve Psikiyatri

Hemşireliği Programı, İstanbul, Türkiye, E-posta: gulsahkorpe@outlook.com ORCID https://orcid.org/o000-00025192-7987

${ }_{* *}$ Prof. Dr., İstanbul Üniversitesi-Cerrahpaşa, Florence Nightingale Hemşirelik Fakültesi, Ruh Sağlığı ve Psikiyatri Hemşireliği Anabilim Dalı, İstanbul, Türkiye, E-posta: leylak73@yahoo.com ORCID https://orcid.org/o00o-0003$\underline{0102-2968}$

ETIK BILLIRIM: Araştırmaya başlamadan önce İstanbul Medipol Üniversitesi Girişimsel Olmayan Klinik Araştırmalar Etik Kurulu Başkanlı̆̆ndan (Tarih: 22.06.2021, Sayı: E-10840098-772.02-2959) etik kurul onayı alınmıştır. 
Results: It was determined that the students had an average of $11.19 \pm 3.84$ points in the dimension of "social network addiction", $11.29 \pm 4.05$ points in the dimension of "instant messaging addiction", 7.74 \pm 3.41 points in the dimension of "online game addiction", and 10.36 4.12 points in the dimension of "web sites addiction". In addition, a statistically significant difference was found between the number of hours spent with technology after the pandemic and the scale score average.

Conclusion: Technology addiction levels of nursing students were found to be low level. The most important issue to be considered when using technology is its intended use, and there should be a limitation in terms of both effort and time according to the current purpose of use. If it is used for entertainment purposes without a purpose and time limit, it may cause undesirable results such as poor use of time or poor time management skills.

Keywords: Nursing students, technology, addiction, Covid-19.

\section{Giriş}

Covid-19 pandemisi tüm dünya gündeminde yüzyılın en büyük salgını olarak ortaya çıkmıştır. Ülkemizde de ilk vaka 11 Mart 2020'de rapor edilmiştir ${ }^{1}$. Covid-19'un neden olduğu salgın süreci yönetilirken dünyadaki hükümetler hastalığın yayılımını önlemek ve salgınla mücadele etmek amacıyla çeşitli kısıtlamalar ve önlemler almak zorunda kalmışlardır. Sosyal izolasyon, karantina, maske kullanımı ve sosyal mesafe gibi önlemler ile yayılım engellenmeye çalışılmıştır. $\mathrm{Bu}$ önlemler kapsamında Türkiye'de de 'evde kal' uygulaması hayata geçirilmiştir ${ }^{2-4}$. Bu uygulama pandeminin başlarında gönüllülük esasına dayansa da kısa bir süre sonra vaka sayılarındaki artışla birlikte sokağa çıkma yasaklarına dönüşmüştür5.

Salgın ile hastalığın yayılımını önlemek amacıyla uygulanan kısıtlamalar, sokağa çıkma yasakları gibi önlemler, bireylerin evde geçirdikleri süreyi artırmıştır. Bireylerin gündelik hayatlarında ve düzenlerinde değişimler meydana gelmiştir. Eğitim-öğretim yöntemleri değişiklik göstermiş, uzaktan ve teknolojik platformlar aracılığıyla süreç yönetilmiştir. İş ve eğitimden sağlık hizmetlerine ve ötesine kadar birçok günlük aktivite, kamusal alanlardan evlere taşındıkça, teknoloji ve internet kullanımı önemli ölçüde artmıştır ${ }^{6,7}$. Pandemi sonrası kısa süre içerisinde düzenin değişmesi ve yeni düzenin oluşturulmasında teknolojinin yeri yadsınamaz boyuttadır. Pandemi sürecinde kullanılan teknolojiler, sosyal kısıtlamaların uygulanabilirliğinde, uzaktan eğitim ve çalışmanın gerçekleşmesinde çok önemli bir rol almıştır5. Çevrimiçi görüşmelerin yapılabilmesi, toplantıların düzenlenebilmesi, bilgisayar ortamlı eğitim - öğretim tabanının oluşturulması öğrenciler arasında eşitsizlikler oluşma olasılığını içerse de sürdürülebilirliği sağlama açısından teknoloji bu alanda etkin bir rol oynamıştır8,9. Bazı insanlar teknoloji kullanımını depresyon, kaygı veya umutsuzluktan kurtulmanın bir yolu olarak görürken ${ }^{10}$, çevrimiçi harcanan zamanın artması, sosyal etkileşim ve entegrasyonda da bir artışa da neden olmuştur ${ }^{11}$.

Bronfenbrenner'in ekolojik sistem teorisine göre ${ }^{12}$, aile ve sosyal çevre ergenlerin teknoloji kullanımını etkileyen önemli faktörlerdir. Pandemi sonrası yapılan birçok çalışmada bu dönemde bireylerin değişen sosyal yaşam koşulları yüzünden duydukları kaygıyı azaltabilmek için internette gezinme, dizi, film ve video izleme, video oyun oynama ve sosyal medya kullanma gibi teknoloji bağımlılığı riski taşıyan davranışlara, pandemi öncesi döneme göre çok daha fazla ilgi gösterdikleri görülmüştür ${ }^{13-15}$. Yapılan çalışmalar ayrıca bilişim teknolojilerinin kullanımını kuşak farkları açısından incelediğinde yüksek kullanım artışının Z kuşağında gerçekleştiğini bulgulamıştır. Y ve X kuşağına göre Z kuşağının \%62 oranla mesajlaşma hizmetlerine daha fazla zaman ayırdı̆̆ı görülmüştür. Y kuşağında bu oran \%45 olarak görülürken, X kuşağında ise \%40 
oranında görülmüştür. Medya türleri açısından yapılan incelemelerde de medya kullanım artışının en yüksek oranla $\mathrm{Z}$ kuşağında gerçekleştiği görülmüşsü̈r ${ }^{16}$.

Global bir kriz haline gelen Covid-19 pandemisinde okulların kapanmasıyla birlikte eğitim sisteminde oluşturulan dijital dönüşüm sebebiyle öğrenciler de bu süreçten etkilenmişlerdir. Bu süreç eğitim-öğretim aşamalarının tümünü etkilemiş, uzaktan eğitime geçilmesini zorunlu kılarak yeni bir eğitim düzeni oluşturulmasına sebep olmuştur. Tüm dünyada eğitim sisteminin hızlı bir değişime uğramasıyla Yüksek Eğitim Kurumu (YÖK) 26 Mart 2020 tarihinden itibaren üniversitelerde eğitim-öğretim faaliyetlerinin çevrimiçi olarak devam ettirilmesi yönünde karar almıştır ${ }^{17}$. Covid-19 salgını hemşirelik öğrencilerini diğer öğrenci grupları kadar etkilemiştir ${ }^{18,19}$. Hemşirelik eğitiminde de diğer bölümlerde olduğu gibi, hemşirelik yüksek öğrenimine yönelik artan talebe yanıt olarak, daha fazla sayıda öğrenciye farklı ortamlarda ve farklı zamanlarda eğitim sağlamak için uzaktan eğitim teknolojileri kullanılmış ve geliştirilmiştir ${ }^{20,21}$. Hemşirelik eğitiminde öğretme ve öğrenme aracı olarak teknoloji kullanımını öne çıkaran aktif web tabanlı öğrenme tekniklerinin (simülasyon senaryoları, film, belgesel, dizi tartışması, çevrimiçi platformlar üzerinden makale ve vaka tartışması vb.) kullanılması tercih edilmiştir ${ }^{17}$.

COVID-19 salgını sırasında teknolojik araçların aşırı kullanımının, özellikle kullanım süresi arttıkça, bağımlılık için bir risk faktörü olma olasılığını iki veya daha fazla kat artırdığı tespit edilmiştir15,22,23. Bu çalışmada Covid-19 döneminde hemşirelik öğrencilerinde teknoloji bağımlılığının düzeyinin belirlenmesi amaçlanmıştır.

\section{Gereç ve Yöntem}

\section{Araştırmanın Tipi}

$\mathrm{Bu}$ çalışma prospektif, tanımlayıcı tipte araştırmadır.

\section{Araştırmanın Evreni ve Örneklemi}

Araştırma evreni İstanbul'da bir vakıf üniversitesinde 2020-2021 Eğitim-Öğretim Yılı Bahar Döneminde lisans öğrenimi gören 820 adet hemşirelik bölümü öğrencisinden oluşmaktadır. Araştırma örneklem sayısı, evreni bilinen örneklem yöntemi kullanılarak belirlenmiştir. Örneklem sayısı, \%5 kabul edilebilir hata payına göre \%95 güven seviyesinde 340 öğrenci olarak hesaplanmıştır. Öğrenciler, "basit rastgele örnekleme" yöntemi ile seçilmiştir. Çalışma, veri kaybı göz önüne alınarak 362 öğrenci ile yürütülmüştür. Bu çalışmanın verileri Haziran-Ağustos 2021 tarihleri arasında toplanmıştır.

\section{Veri Toplama Formları}

Çalışmada verilerin toplanmasında Sosyodemografik Form ve Teknoloji Bağımlılı̆̆ı Ölçeği kullanılmıştır.

\section{Sosyodemografik Form:}

Sosyodemografik form öğrencilerin cinsiyet, yaş, medeni durum, üniversite eğitimince kaldığı yer, aile tipi, gelir durumu, Covid-19 tanısı alma, Covid-19 döneminde teknoloji kullanımında artma, pandemi öncesi ve sonrası teknoloji kullanım saati ve en çok kullandığı teknolojik alet sorularını içeren 12 maddeden oluşmaktadır.

\section{Teknoloji Bağımlılı̆̆ı Ölçeği (ТВÖ):}

Aydın tarafından 2017 yılında geliştirilen ölçek 24 madde ve 4 alt boyuttan oluşmaktadır. Beşli likert formatında hazırlanan ölçekte teknoloji bağımlılığının düzeyini belirlemek amaçlanmıştır. Ölçekte derecelendirme, soru maddeleri 1 "hiçbir zaman”, 2 "nadiren”, 3 "orta sıklıkta”, 4 "çok 
sık", 5 "her zaman" olarak ele alınmaktadır. Ölçeğin değerlendirmesinde toplam puan maddelere verilen yanıtların toplanmasıyla elde edilir. Ölçeğin toplam puan ortalaması yorumlanırken 0-24 arası "Bağımlı değil”, 25-48 arası "Düşük düzeyde bağımlı", 49-72 arası "Orta düzeyde bağımlı", 73-96 arası "Oldukça Bağımlı”, 97-120 arası ise "Tam Bağımlı” olarak kabul edilmiştir. Ölçeğe ait alt boyutların Cronbach's alfa değerleri, şu şekildedir: Çevrimiçi Oyun Bağımlılığı; 0,897, Sosyal A $\breve{g}$ Bağımlılığı; 0,786, Web Siteleri Bağımlılı̆̆ı; 0,861, Anlık Mesajlaşma Bağımlılı̆̆ı; 0,80624.

\section{Verilerin Toplanması}

Öğrencilere araştırmanın amacı, verilerin nasıl toplanacağı ve toplanan verilerin yalnızca bilimsel amaç dâhilinde kullanılacağı açıklanmıştır. Araştırmaya katılmaya gönüllü olan öğrencilerden çevrimiçi platformda izin alınmıştır. Veriler Haziran-Ağustos 2021 tarihleri arasında çevrimiçi platform kullanılarak toplanmıştır.

\section{Etik Konular}

Araştırmaya başlamadan önce İstanbul Medipol Üniversitesi Girişimsel Olmayan Klinik Araştırmalar Etik Kurulu Başkanlığından (Tarih: 22.06.2021, Sayı: E-10840098-772.02-2959) etik kurul onayı ve katılımcılardan çevrimiçi onamları alınmıştır.

\section{Veri Analizi}

Araştırmada verilerin analizi SPSS 22.0 paket programı kullanılarak yapılmıştır. Verilerin çözümlenmesinde tanımlayıcı analiz için yüzde ve frekans değerleri kullanılmıştır. Yapılan Shapiro-Wilk testine göre çalışma verileri normal dağılım göstermediğinden iki değişken grubun karşılaştırılmasında Mann-Whitney U Testi, ikiden fazla sayıda grubun karşılaştırılmasında Kruskal Wallis-H Testi kullanılmıştır. İkiden fazla alt gruba sahip verilerde çıan anlamlılığın hangi alt gruptan kaynaklandığını belirlemek amaciyla gruplara Bonferroni düzeltmeli MannWhitney U testi yapılmıştır.

\section{Bulgular}

Öğrencilerin \%87,8’i kadın, \%52,2'si 20 yaşın üstünde, \%97'si bekar ve \%37'si 3.sınıfta bulunmaktadır. \%88,1 üniversite eğitimi süresince ailesiyle birlikte yaşamakta ve \%91,4'ü çekirdek aile yapısına sahiptir. \%69,6'sının geliri giderine eşittir. Öğrencilerin \%93,9’u Covid-19 tanısı almamıştır. \%85,6'sı Covid-19 döneminde teknoloji kullanımlarının arttığını ifade etmiştir. Pandemi öncesinde \%35,9'u teknoloji kullanımına 2 saat ayırdığını, pandemi sonrası ise \%44,2'si 5 saat ve daha fazla süreyi teknoloji kullanımına ayırdığını belirtmiştir. Öğrencilerin pandemi süresince en çok kullandıkları teknolojik alet ise \%52,2 oranla cep telefonu olarak bulunmuştur (Tablo 1).

Öğrencilerin Teknoloji bağımlılığı ölçeği toplam puan ortalaması 40,5912,50 olarak bulunmuştur. Öğrencilerin cinsiyet, yaş, medeni durum, üniversite eğitimi süresince kaldığı yer, aile tanımı, ekonomik durum, Covid-19 tanısı alma, Covid-19 döneminde teknoloji kullanımında artma, pandemi öncesi teknoloji ile geçirilen süre ve pandemi süresince en çok kullanılan teknolojik alet özellikleri ile TBÖ puan ortalamaları arasında istatistiksel açıdan anlamlı fark bulunmamıştır (Tablo 1).

Öğrencilerin pandemi sonrası teknoloji ile geçirdikleri saat ile TBÖ puan ortalamaları $\left(\mathrm{X}^{2}=10,603 ; \mathrm{p}=0,031\right)$ arasında istatistiksel açıdan anlamlı fark bulunmuştur (Tablo 1). Pandemi sonrası ile teknolojiye 3 saat ayıran öğrencilerin puan ortalamaları 2 saat, 4 saat ve 5 saat ve daha fazla ayıran öğrencilerden daha yüksek bulunmuştur (Tablo 1). 
Tablo 1. Öğrencilerin sosyodemografik özellikleri ile TBÖ puan ortalamaları $(n=362)$

\begin{tabular}{|c|c|c|}
\hline Tanıtıcı Özellikler & & TBÖ \\
\hline & n (\%) & Ort \pm SS \\
\hline \multicolumn{3}{|l|}{ Cinsiyet } \\
\hline Kadın & $318(87,8)$ & $40,83 \pm 12,66$ \\
\hline Erkek & $44(12,2)$ & $38,86 \pm 11,24$ \\
\hline \multicolumn{2}{|l|}{ Test değeri } & $\mathrm{Z}=-0,771 ; \mathrm{p}=0,441$ \\
\hline \multicolumn{3}{|l|}{ Yaş } \\
\hline $18-20$ & $173(47,8)$ & $41,16 \pm 12,72$ \\
\hline$\geq 21$ & $189(52,2)$ & $40,07 \pm 12,30$ \\
\hline \multicolumn{2}{|l|}{ Test değeri } & $\mathrm{Z}=-0,825 ; \mathrm{p}=0,409$ \\
\hline \multicolumn{3}{|l|}{ Medeni durum } \\
\hline Bekar & $351(97,0)$ & $40,46 \pm 12,50$ \\
\hline Evli & $11(3,0)$ & $44,72 \pm 12,19$ \\
\hline \multicolumn{2}{|l|}{ Test değeri } & $\mathrm{Z}=-1,307 ; \mathrm{p}=0,191$ \\
\hline \multicolumn{3}{|l|}{ Sinif } \\
\hline 1.Sinif & $58(16,0)$ & $41,01 \pm 11,83$ \\
\hline 2.sinif & $103(28,5)$ & $40,49 \pm 13,30$ \\
\hline 3.sinif & $134(37,0)$ & $40,71 \pm 12,53$ \\
\hline 4.Sinif & $67(18,5)$ & $40,14 \pm 12,00$ \\
\hline \multicolumn{2}{|l|}{ Test değeri } & $\chi^{2}=0,427 ; p=0,935$ \\
\hline \multicolumn{3}{|c|}{ Üniversite eğitimi süresince kaldığı yer } \\
\hline Aileyle & $319(88,1)$ & $40,74 \pm 12,43$ \\
\hline Arkadaşlarıyla birlikte evde & $32(8,8)$ & $38,81 \pm 12,28$ \\
\hline Tek başına evde & $11(3,0)$ & $41,45 \pm 15,68$ \\
\hline \multicolumn{2}{|l|}{ Test değeri } & $\chi^{2}=0,865 ; p=0,649$ \\
\hline \multicolumn{3}{|l|}{ Aile Tanımı } \\
\hline Çekirdek aile & $331(91,4)$ & $40,65 \pm 12,45$ \\
\hline Geniş aile & $31(8,6)$ & $39,96 \pm 13,19$ \\
\hline \multicolumn{2}{|l|}{ Test değeri } & $\mathrm{Z}=-1,307 ; \mathrm{p}=0,191$ \\
\hline \multicolumn{3}{|l|}{ Ekonomik durum } \\
\hline Gelir giderden fazla & $77(21,3)$ & $40,77 \pm 11,46$ \\
\hline Gelir giderden az & $33(9,1)$ & $40,63 \pm 13,58$ \\
\hline Gelir gidere eşit & $252(69,6)$ & $40,53 \pm 12,70$ \\
\hline
\end{tabular}




\begin{tabular}{|c|c|c|}
\hline \multicolumn{2}{|l|}{ Test değeri } & $\chi^{2}=0,307 ; p=0,858$ \\
\hline \multicolumn{3}{|c|}{ Covid-19 tanısı alma } \\
\hline Evet & $22(6,1)$ & $37,68 \pm 10,48$ \\
\hline Hayır & $340(93,9)$ & $40,78 \pm 12,61$ \\
\hline \multicolumn{2}{|l|}{ Test değeri } & $\mathrm{Z}=-1,091 ; \mathrm{p}=0,275$ \\
\hline \multicolumn{3}{|c|}{ Covid-19 döneminde teknoloji kullanımında artma } \\
\hline Evet & $310(85,6)$ & $40,44 \pm 12,58$ \\
\hline Hayır & $52(14,4)$ & $41,50 \pm 12,10$ \\
\hline \multicolumn{2}{|l|}{ Test değeri } & $\mathrm{Z}=-0,766 ; \mathrm{p}=0,444$ \\
\hline \multicolumn{3}{|c|}{ Pandemi öncesi teknoloji ile geçirilen süre } \\
\hline 1 saat & $43(11,9)$ & $42,02 \pm 11,67$ \\
\hline 2 saat & $130(35,9)$ & $40,11 \pm 12,34$ \\
\hline 3 saat & $92(25,4)$ & $40,39 \pm 12,93$ \\
\hline 4 saat & $53(14,6)$ & $40,39 \pm 12,59$ \\
\hline 5 ve daha fazla saat & $44(12,1)$ & $41,29 \pm 13,17$ \\
\hline \multicolumn{2}{|l|}{ Test değeri } & $\chi^{2}=1,505 ; p=0,826$ \\
\hline \multicolumn{3}{|c|}{ Pandemi sonrası teknoloji ile geçirilen saat } \\
\hline 1 saat & $19(5,2)$ & $41,78 \pm 11,00$ \\
\hline 2 saat & $20(5,5)$ & $36,85 \pm 11,79^{a}$ \\
\hline 3 saat & $67(18,5)$ & $44,77 \pm 14,01^{\text {abc }}$ \\
\hline 4 saat & $96(26,5)$ & $39,55 \pm 11,31^{b}$ \\
\hline 5 saat ve daha fazla & $160(44,2)$ & $39,80 \pm 12,49^{c}$ \\
\hline \multicolumn{2}{|l|}{ Test değeri } & $\chi^{2}=10,603 ; p=0,031$ \\
\hline \multicolumn{3}{|c|}{ Pandemi süresince en çok kullanılan teknolojik alet } \\
\hline Cep telefonu & $189(52,2)$ & $40,15 \pm 11,88$ \\
\hline Bilgisayar & $105(29,0)$ & $41,31 \pm 14,08$ \\
\hline Tablet & $34(9,4)$ & $42,52 \pm 13,94$ \\
\hline Televizyon & $34(9,4)$ & $38,91 \pm 8,75$ \\
\hline \multicolumn{2}{|l|}{ Test değeri } & $\chi^{2}=0,718 ; p=0,869$ \\
\hline Toplam & $362(100,0)$ & $40,59 \pm 12,50$ \\
\hline
\end{tabular}

Ort: ortalama, SS: Standart sapma, Z: Mann -Whitney U testi, $\chi 2$ : Kruskal Wallis-H testi, p <0,05 a,b,c: Bonferroni düzeltmeli Mann-Whitney U testine göre aralarında istatistiksel açıdan bir fark vardır. 
Öğrencilerin ТВÖ alt boyutlarına göre puan ortalamalarının "sosyal ağ bağımlılığı” boyutunda

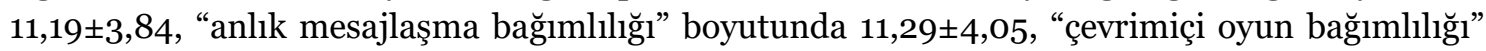
boyutunda $7,74 \pm 3,41$, "web siteleri bağımlılı̆̆ı" boyutunda 10,36 $\pm 4,12$ olduğu belirlenmiştir (Tablo 2).

Tablo 2. Öğrencilerin TBÖ alt boyutları puan ortalamaları $(n=362)$

\begin{tabular}{|l|l|l|l|}
\hline TBÖ Alt Boyutları & Min - Max & Ort & SS \\
\hline Sosyal Ă̆ Bağımlılı̆̆ı & $6-23$ & 11,19 & 3,84 \\
\hline Anlık Mesajlaşma Bağımlılığı & $6-23$ & 11,29 & 4,05 \\
\hline Çevrimiçi Oyun Bağımlılı̆̆ı & $6-27$ & 7,74 & 3,42 \\
\hline Web Siteleri Bağımlılığı & $6-25$ & 10,36 & 4,12 \\
\hline
\end{tabular}

Ort: ortalama, SS: Standart sapma, Min: Minimum, Max: Maksimum

\section{Tartışma}

Bu çalışma İstanbul'da bir üniversitede öğrenim gören hemşirelik öğrencilerinin Covid-19 pandemisi döneminde teknoloji bağımlılı̆̆ düzeylerini belirlemek amacıyla yapılmıştır. Pandemi döneminde; zorunlu sosyal izolasyon, arkadaşlarından ayrı kalma, okulların kapanması ile eğitimin online olarak yürütülmesi gibi sebeplerden ötürü öğrenciler teknolojiyi daha uzun süreli kullanmak durumunda kalmışlardır²5.

Araştırmada Covid-19 pandemisi sürecinde hemşirelik öğrencilerinin teknoloji bağımlılı̆̆ düşük düzeyde bağımlı olarak bulunmuştur. Aynı şekilde öğrencilerin TBÖ alt boyutlarını oluşturan sosyal ă̆, anlık mesajlaşma, çevrimiçi oyun ve web siteleri bağımlılıkları da düşük düzey bağımlı olarak belirlenmiştir. Arslan (2020) üniversite öğrencilerinde yaptığı çalışmasında öğrencilerin dijital bağımlılık düzeylerinin orta düzeyde olduğunu belirlemiştir²6.

Teknoloji bağımlılığı literatürde çoğunlukla internet bağımlılığı, sosyal medya bağımlılı̆̆ı ve dijital oyun bağımlılığı ile ilişkilendirilmektedir ve daha çok internetin yüksek oranda kullanılma isteğinin önüne geçilememesi ile ortaya çıkmaktadır ${ }^{27}$. Bu konuya ilişkin yapılan çalışmalarda internet bağımlılığı ile ilgili çeşitli sonuçlar bulunmaktadır. Kaess ve diğerlerinin 11 Avrupa ülkesinde 11.356 ergenle gerçekleştirdikleri çalışmada ergenlerde internet bağımlılığı oranı \%4,2, sorunlu internet kullanımı oranı ise \%13,4'tür ${ }^{28}$. Sağlık alanında öğrenim gören öğrencilerde internet bağımlılığı ile ilgili yapılan araştırmalarda öğrencilerin internette çok fazla zaman geçirdiği ve internet bağımlılığı açısından risk taşıdığı ortaya çıkmıştır29,30.

Teknoloji bağımlılığının alt boyutlarından biri olan çevrimiçi oyun bağımlılığı çalışmamızda düşük düzeyde bulunmuştur. Aktaş ve Daşdan (2021) yaptıkları çalışmada üniversite öğrencilerinin \%6,3’ünün dijital oyun bağımlısı ve \%1,6’sının ise yüksek düzeyde dijital oyun bağımlısı grubunda yer aldığını belirlemişlerdir31. Oyun bağımlılığına yönelik yapılan Miezaha ve arkadaşlarının çalışmasında ${ }^{2}$ \%12,2', Li ve arkadaşlarının çalışmasında33 ise \%4,7 olarak belirlenmiştir.

Çalışmamızda cinsiyet, yaş, medeni durum, üniversite eğitimi süresince kaldığı yer, aile tanımı, ekonomik durum, Covid-19 tanısı alma, Covid-19 döneminde teknoloji kullanımında artma, pandemi öncesi teknoloji ile geçirilen süre ve pandemi süresince en çok kullanılan teknolojik alet özellikleri ile teknoloji bağımlılı̆̆ı arasında bir ilişki bulunamamıştır. 
Teknoloji bağımlılığı ile ilgili yapılan çalışmalarda34,-36 araştırmamızın aksine öğrencilerin yaşı ile internet bağımlılığı arasında negatif yönde bir ilişki olduğu, yaşı daha genç olanlarda internet bağımlılığının daha fazla olduğu belirtilmiştir. Yine bu durumu örneklem grubunun yakın yaş aralığında olması ile ilişkilendirebiliriz.

Çalışmamızda öğrencilerin bulundukları sınıf ve teknoloji bağımlılığı arasında bir ilişki bulunamazken yapılan diğer çalışmalarda öğrencilerin sınıfları ile internet bağımlılığı arasında negatif34,37 ya da pozitif yönde bir ilişki olduğu belirtilmektedir36,38.

Çalışma sonuçlarımızın aksine, Eryılmaz ve Çukurluöz (2018) Ankara'da lise öğrencilerinin dijital bağımlılıklarını inceledikleri çalışmada; öğrencilerin telefonlarına, internet ve sosyal medyaya bağımlı olduğu, erkeklerin kız öğrencilere göre daha yüksek oranda dijital bağımlı olduğu, sosyal medya bağımlılığında ise kızların daha bağımlı olduğu belirlenmiştir39. Demir ve Kumcağız (2019) üniversite öğrencileri ile gerçekleştirdikleri çalışmada ise çalışmalarında cinsiyetin sosyal medya kullanımı üzerinde anlamlı olmadığını belirlemişlerdir ${ }^{40}$.

Yapılan çalışmalar arasındaki farklar, çalışmalarda alınan örneklem büyüklüğü, veri toplama amacıyla kullanılan değerlendirme materyallerinin farklılı̆̆ ve farklı zaman aralıklarında, farklı topluluklarda yapılmış olmasından ötürü oluşabileceği düşünülmektedir.

Araştırmamızda pandemi sonrası teknoloji ile geçirilen süre ile teknoloji bağımlılığı arasında anlamlılık bulunmuştur. Pandemi sonrası teknoloji ile 3 saat geçiren öğrencilerin bağımlılıkları 2, 4 ve 5 saat ve üstü geçiren öğrencilere göre daha yüksek bulunmuştur. Ulutaşdemir ve arkadaşlarının (2017) sağlık bölümünde okuyan üniversite öğrencileri ile yaptıkları ve internet bağımlılığını araştırdıkları çalışmasında internet bağımlısı olmayanların haftada 1 saat, bağımlı olanlarınsa haftada 40 saat internet kullandığ öğrencilerinin sosyal medya kullanım sıklıklarını araştırdığı çalışmasında öğrencilerin internet kullanımının çoğunlukla her gün 5-6 saat aralığında olduğunu ve kullanma sebebinin ise arkadaşlarla iletişim kurmak olduğunu belirlemiştir42 ${ }^{2}$ Sülün ve arkadaşlarının yaptıkları araştırmada, ergenlerin \%40’ının Covid-19 sürecinde akıllı telefonlarını tüm gün kullandığı belirlenmiştir43. Dong ve arkadaşlarının yaptıkları çalışmada, pandemi sürecinde çocuk ve ergenlerin yarısının telefon gibi elektronik cihazları tüm gün kullanırken, pandemiden önce ise sadece \%27'sinin cihazları tüm gün kullandığını bulgulamışlardır44. Bu bulgular araştırmamızın bulgularını destekler niteliktedir. Eğitim hayatının çevrimiçi olarak gerçekleşmesi bu artışın sebebi olarak düşünülmektedir.

Covid-19 pandemisinin başlangıcından bu zamana kadar yapılan çalışmalar43,45-47 teknoloji bağımlılığı oranlarında yükselme olduğunu göstermekte olup, bizim çalışmamız da bu konuya ilişkin literatür ile benzerlik göstermektedir.

Çalışmamızın sınırlılıkları, çalışmada verilerin yalnızca bir üniversitede bulunan hemşirelik öğrencilerinden toplanması sebebiyle çalışma sonuçları bu öğrencileri kapsamakta olup, genellenemez niteliktedir.

\section{Sonuç ve Öneriler}

Çalışmamızın sonucunda hemşirelik öğrencilerinin düşük düzeyde teknoloji bağımlısı olduğu ve pandemi sonrasında teknoloji ile geçirilen sürenin teknoloji bağımlılığını etkilediği belirlenmiştir. Son yıllarda yapılan çalışmalarda üniversite öğrencilerinde teknoloji bağımlılığı gelişme oranları yüksektir. Bu sebeple özellikle riskli grupların belirlenerek uygun müdahalelerin planlanması önem taşımaktadır. Bu amaçla öğrencilere, ailelere ve akademisyenlere farkındalık eğitimleri düzenlenebilir. 
Çıkar Çatışması: Araştırmada çıkar çatışması bulunmamaktadır.

Araştırma Etik Onayı: Araştırma için İstanbul Medipol Üniversitesi Girişimsel Olmayan Klinik Araştırmalar Etik Kurulu Başkanlığından (Tarih: 22.06.2021, Sayı: E-10840098-772.022959) etik kurul onayı ve katılımcılardan gönüllü olarak çalışmaya katıldıklarına ilişkin onam alınmıştır. Araştırmanın tüm giderleri yazarlar tarafından karşılanmıştır.

\section{KAYNAKLAR}

1. T.C. Sağlık Bakanlığı Halk Sağlığı Genel Müdürlüğü. COVID-19 (Sars-Cov-2 Enfeksiyonu) Genel Bilgiler, Epidemioloji ve Tamı. Ankara: Sağlık Bakanlığı; 2020.

2. Rundle AG, Park Y, Herbstman JB, et al. COVID-19 related school closings and risk of weight gain among children. Obesity. 2020;28(6):1008-1009.

3. Golberstein E, Wen H, Miller BF. Coronavirus disease 2019 and mental health for children and adolescents. JAMA Pediatr. 2020;174(9):819-820.

4. Ornell F, Schuch JB, Sordi AO, Kessler FHP. Pandemic fear and COVID-19: Mental health burden and strategies. Braz J Psychiatry. 2020;42(3):232-235.

5. Öztürk A. COVID-19 pandemi sürecinde bilişim teknolojileri bağımlılı̆̆ı. A ğr İbrahim Çeçen Üniversitesi Sosyal Bilimler Enstitüsü Dergisi. 2021;7(1):195-219.

6. Ahorsu DK, Lin CY, Imani V, Saffari M, Griffiths MD, Pakpour AH. The fear of COVID-19 scale: Development and initial validation. International Journal of Mental Health and Addiction. 2020;1-9. https://doi.org/10.1007/s11469-020-00270-8.

7. King DL, Delfabbro PH, Billieux J, Potenza MN. Problematic online gaming and the COVID-19 pandemic. Journal of Behavioral Addictions. 2020;9(2):184-186. https://doi.org/10.1556/ 2006.2020.00016.

8. Özbay Ö. Dünyada ve Türkiye'de uzaktan eğitimin güncel durumu. Uluslararası Eğitim Bilimleri Dergisi. 2015;2(5):376-394. https://doi.org/10.16991/1nesjournal.174.

9. Özer M. Educational policy actions by the ministry of national education in the times of COVID-19. Kastamonu Education Journal. 2020;28(3):1124-1129. https://doi.org/10.24106/kefdergi.722280.

10. Hinić D, Mihajlović G, Špirić Ž, Dukić Dejanović S, Jovanović M. Excessive internet use: addiction disorder or not? Vojnosanitetski Pregled. 2008;65(10):763767. https://doi.org/10.2298/VSPo810763H.

11. Magsamen-Conrad K, Billotte-Verhoff C, Greene K. Technology addiction's contribution to mental wellbeing: The positive effect of online social capital. Computers in Human Behavior. 2014;40:23-30. https://doi.org/10.1016/j.chb.2014.07.014.

12. Shelton LG. The Bronfenbrenner Primer: A Guide to Develecology. 1st ed. London: Routledge; 2018.

13. Majeed M, Irshad M, Fatima T, Khan J, Hassan MM. Relationship between problematic social media usage and employee depression: A moderated mediation model of mindfulness and fear of COVID-19. Front. Psychol. 2020;11(557987). 
14. Gao J, Zheng P, Jia Y, et al. Mental health problems and social media exposure during COVID-19 outbreak. PLoS One. 2020;15(4).

15. Király O, Potenza MN, Stein DJ, et al. Preventing problematic internet use during the COVID-19 pandemic: Consensus guidance. Comprehensive Psychiatry. 2020;100:152180. https://doi.org/10.1016/j.comppsych.2020.152180.

16. Göker ME, Turan Ş. Covid-19 pandemisi sürecinde problemli teknoloji kullanımı. ESTÜDAM Halk Sağhğı Dergisi. 2020;5(COVID-19 Özel Sayısı):108-114.

17. Küçük L. Editorial. J Psy Nurs. 2021;12(1): v.

18. Turan N, Durgun H, Kaya H, et al. Relationship between nursing students' levels of internet addiction, loneliness, and life satisfaction. Perspectives in Psychiatric Care. 2020;56:598604. https://doi.org/10.1111/ppc.12474.

19. Subedi S, Nayaju S, Subedi S, Shah SK, Shah JM. Impact of e-learning during COVID-19 pandemic among nursing students and teachers of Nepal. Int $J$ Sci Healthc Res. 2020;5(3):68-76.

20. Özdemir NG, Turan N, Kaya H. Significance of technology-based environment in the development of nursing students' critical thinking skills. Press Academia Procedia. 2017;4(1):74-79. https://doi.org/10.17261/Pressacademia.2017.520.

21. Morin KH. Nursing education after COVID-19: same or different? J Clin Nurs. 2020; 29:3117-3119. https://doi.org/10.1111/jocn.15322.

22. Aliyev J. Digital detox important in COVID-19 era: Expert. 2020. https://www.aa.com.tr/en/health/digital-detoximportant-in-covid-19-eraexpert/1804327.

23. Winther DK, Byrne J. Rethinking screen-time in the time of COVID-19. UNICEF for every child. 2020. https://www. unicef.org/globalinsight/stories/rethinking-screen-time-timecovid19.

24. Aydın F. Teknoloji Bağımlılığının Sınıf Ortamında Yarattığ Sorunlara İlişkin Öğrenci Görüşleri. [yüksek lisans tezi]. Ankara, Türkiye: Ankara Üniversitesi Eğitim Bilimleri Enstitüsü; 2017.

25. Cao W, Fang Z, Hou G,et al. The psychological impact of the COVID-19 epidemic on college students in China. Psychiatry Res. 2020;287:112934.

26. Arslan A. Üniversite öğrencilerinin dijital bağımlılık düzeylerinin çeşitli değişkenler açısından incelenmesi. International e-Journal of Educational Studies. 2020;4(7):27-41.

27. Van Rooij A, Prause N. A critical review of "internet addiction" criteria with suggestions for the future. J Behav Addict. 2014;3(4):203-213. https://doi.org/10.1556/JBA.3.2014.4.1.

28. Kaess M, Durkee T, Brunner R, et al. Pathological Internet use among European adolescents: psychopathology and self-destructive behaviours. European Child \& Adolescent Psychiatry. 2014;23(11):1093-1102.

29. Gedam SR, Shivji IA, Goyal A, Modi L, Ghosh S. Comparison of internet addiction, pattern, and psychopathology between medical and dental students. Asian J Psychiatr. 2016;22:105-10.24. 
30. Srijampana VVGR, Endreddy AR, Prabhath K, Rajana B. Prevalence, and patterns of internet addiction among medical students. Medical Journal of Dr. D.Y. Patil University. 2014;7(6):709-13.

31. Aktaş B, Daştan NB. Covid-19 pandemisinde üniversite öğrencilerindeki oyun bağımlılığı düzeyleri ve pandeminin dijital oyun oynama durumlarına etkisi. Bağımlılık Dergisi. 2021;22(2):129-138.

32. Miezaha D, Batchelora J, Megreyab AM, et al. Video computer game addiction among university students in ghana: Prevalence, correlates and effects of some demographic factors. Psychiatry and Clinical Psychopharmacology. 2020;30(1):17-23.

33. Li H, Zou Y, Wang J, Yang X. Role of stressful life events, avoidant coping styles, and neuroticism in online game addiction among college students: A moderated mediation model. Front Psychol. 2016;7:1794.

34. Al-Gamal E, Alzayyat A, Ahmad MM. Prevalence of internet addiction and its association with psychological distress and coping strategies among university students in Jordan. Perspect Psychiatr Care. 2016;52(1):49-61.

35. Anand N, Thomas C, Jain PA, et al. Internet use behaviors, internet addiction and psychological distress among medical college students: A multicentre study from South India. Asian J Psychiatr. 2018;37:71-7.

36. Bhandari PM, Neupane D, Rijal S, Thapa K, Mishra SR, Poudyal AK. Sleep quality, internet addiction and depressive symptoms among undergraduate students in Nepal. BMC Psychiatry. 2017;21;17(1):106.

37. Azizi SM, Soroush A, Khatony A. The relationship between social networking addiction and academic performance in Iranian students of medical sciences: A cross-sectional study. BMC Psychol. 2019;7(1):28.

38. Hasan AA, Jaber AA. Prevalence of internet addiction, its association with psychological distress, coping strategies among undergraduate students. Nurse Educ Today . 2019;81:7882.

39. Eryılmaz S, Çukurluöz Ö. Lise öğrencilerinin dijital bağımlılıklarının incelenmesi: Ankara ili, Çankaya ilçesi örneği. Elektronik Sosyal Bilimler Dergisi. 2018;17(67):889-912.

40. Demir Y, Kumcağız H. Üniversite öğrencilerinin sosyal medya bağımlılığının farklı değişkenler açısından incelenmesi. Türk Psikolojik Danışma ve Rehberlik Dergisi. 2019;9(52):23-42.

41. Ulutaşdemir N, Sergek E, Bakır E, Deniz E. Geleceğin sağlık profesyonellerinde internet bağımlılığının yaşam kaliteleri üzerine etkisi. Zeynep Kamil Tip Bülteni. 2017;48(2):,4448.

42. Aydın İE. Üniversite öğrencilerinin sosyal medya kullanımları üzerine bir araştırma: Anadolu üniversitesi örneği. Selçuk Üniversitesi Sosyal Bilimler Enstitüsü Dergisi. 2016;(35):373-386.

43. Sülün AA, Yayan EH, Düken ME. COVID-19 salgını sürecinin ergenlerde akıllı telefon kullanımına ve uyku üzerine etkisi. Turk J Child Adolesc Ment Health. 2021;28(1):35-40. 
44. Dong H, Yang F, Lu X, Hao W. Internet addiction and related psychological factors among children and adolescents in China during the coronavirus disease 2019 (COVID-19) epidemic. Front Psychiatry. 2020;11:00751.

45. Elhai JD, Yang H, McKay D, Asmundson GJG. COVID-19 anxiety symptoms associated with problematic smartphone use severity in Chinese adults. $J$ Affect Disord. 2020;274:576-82.

46. Ndubuaku V, Inim V, Ndudi UC, Samuel U, Prince AI. Effect of social networking technology addiction on academic performance of university students in Nigeria. International Journal of Recent Technology and Engineering (IJRTE). 2020;173180 .

47. Khaleel M. Technology addiction among students. Psychology and Education Journal. 2021;58(3):3646-3655. 